\title{
Clinical cardiac involvement in thrombotic thrombocytopenic purpura: a systematic review
}

\author{
Beau M. Hawkins, Mazen Abu-Fadel, Sara K. Vesely, and James N. George
}

BACKGROUND: Autopsy studies consistently demonstrate cardiac involvement in thrombotic thrombocytopenic purpura (TTP), but clinical evidence for cardiac abnormalities is rarely reported.

STUDY DESIGN AND METHODS: This systematic review addresses the apparent discrepancy between autopsy and clinical data. English language articles were identified by keywords for both TTP and for cardiac symptoms, testing, or events. Patients were analyzed if they were more than 10 years old with idiopathic TTP.

RESULTS: Thirty articles were identified that described 111 eligible patients: 20 case reports described 27 patients, 9 retrospective cohort studies described 74 patients, and 1 prospective cohort study described 10 patients. Cardiac events included infarction (26 patients), congestive failure (17), arrhythmias (10), cardiogenic shock (6), and sudden cardiac death (8). Mortality was assessed in 101 patients: 55 died, and 48 autopsies were described. All demonstrated cardiac microvascular thrombi, hemorrhage, and/or necrosis. Follow-up information was reported in only 6 of the 16 patients who survived a cardiac event (follow-up duration, 10 days-2 years; median, 7 weeks).

CONCLUSIONS: The frequency and sequelae of clinical cardiac abnormalities in TTP cannot be accurately assessed because most patients were described in reports of few selected patients; many patients were reported before the availability of effective treatment for TTP and sensitive tests for cardiac involvement. Continuing case reports and cohort studies, however, suggest that cardiac abnormalities may be important and often unrecognized causes of mortality and morbidity in patients with TTP. Prospective studies are needed to determine if cardiac therapy can improve survival and long-term outcomes of patients with TTP.

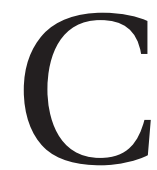

ardiac involvement in patients with thrombotic thrombocytopenic purpura (TTP) has been apparent since the initial case report. ${ }^{1}$ Subsequent reviews of published case reports during the era before effective treatment consistently documented that the heart was one of the most frequently involved organs at autopsy examination..$^{2-4}$ With the advent of effective plasma exchange treatment, mortality from TTP has decreased from 90 percent $^{2}$ to approximately 20 percent; ${ }^{5}$ however, autopsy examinations continue to document extensive cardiac involvement. ${ }^{4,6}$ In spite of these consistent pathologic observations, cardiac symptoms and clinical cardiac abnormalities are rarely described. For example, in 13 case series of 50 or more patients published since 1990,5,7-18 none mentioned cardiac symptoms or clinical cardiac abnormalities in patients with idiopathic TTP. Whether clinical cardiac abnormalities in patients with TTP are uncommon or unrecognized is unclear.

Our review was motivated by four questions important for the care of patients with TTP. 1) What is the frequency of clinical cardiac abnormalities in patients with TTP using sensitive methods to detect myocardial ischemia and cardiac dysfunction? 2) Is cardiac

ABBREVIATIONS: EKG(s) = electrocardiogram(s); HUS = hemolytic-uremic syndrome; TTP = thrombotic thrombocytopenic purpura.

From the Department of Medicine, College of Medicine, and the Department of Biostatistics and Epidemiology, College of Public Health, The University of Oklahoma Health Sciences Center, Oklahoma City, Oklahoma

Address reprint requests to: James N. George, MD, The University of Oklahoma Health Sciences Center, HematologyOncology, Room CHB-358, PO Box 26901, Oklahoma City, OK 73190; e-mail: james-george@ouhsc.edu.

Financial support was provided by The Hematology Research Fund, University of Oklahoma Health Sciences Center. Received for publication June 12, 2007; accepted July 24, 2007.

doi: 10.1111/j.1537-2995.2007.01534.x

TRANSFUSION 2008;48:382-392. 
involvement an important cause of the continuing mortality of patients with TTP? 3) Does abnormal cardiac function persist in patients after recovery from an acute episode of TTP? 4) Can identification of cardiac involvement and appropriate treatment reduce mortality in patients with TTP and diminish symptoms of decreased endurance after recovery from TTP?

To address these questions and the apparent discrepancy between the autopsy and clinical cardiac involvement, we used the method for systematic reviews of published reports ${ }^{19}$ to determine the nature and frequency of cardiac symptoms, testing, and events during the clinical course of patients with TTP. We also documented observations on follow-up of cardiac events and results of autopsies in patients who had had clinically demonstrated cardiac abnormalities. Identification of cardiac abnormalities in these patients may provide a better understanding of the potential risks associated with TTP as well as an opportunity for additional effective treatment.

\section{MATERIALS AND METHODS}

\section{Data sources and search strategy}

Ovid software was used to search the Medline database through February 1, 2007. Articles containing both a TTPrelated keyword in the title or available text (thrombotic thrombocytopenic purpura, TTP, hemolytic-uremic syndrome, HUS, thrombotic thrombocytopenic purpurahemolytic uremic syndrome, TTP-HUS, thrombotic microangiopathy, TMA, microangiopath, intravascular hemolysis, plasma exchange, plasmapheresis) and a cardiac-related keyword in the title or available text (chest pain, angina, troponin, cardiac enzymes, creatinine kinase, echocardiogram, echo, myocardial infarction, MI, myocardial necrosis, heart failure, CHF, cardiogenic shock, sudden cardiac death) were retrieved. Retrieved articles were limited to English language. Bibliographies of retrieved articles were searched to identify additional relevant articles.

\section{Article selection}

Articles were selected if they contained original data on at least one patient described as having TTP, HUS, or thrombotic microangiopathy who was also described as having at least one of the following cardiac-related abnormalities or assessments: 1) cardiac symptoms, including chest pain, angina, dyspnea, orthopnea, or syncope; 2) cardiac testing including electrocardiogram, echocardiogram, coronary angiography, or measurement of cardiac-related serum enzymes (articles with both positive or negative results of the tests were selected); or 3) cardiac events defined as myocardial infarction, congestive heart failure, shock, arrhythmia, and sudden cardiac death. Autopsy data were analyzed only in patients selected because they had cardiac symptoms, testing, or events.

\section{Patient selection}

The goal of our review was to focus on patients with idiopathic TTP because their disease is the result of systemic microvascular thrombosis and they continue to have significant mortality and morbidity in spite of the current therapy with plasma exchange and immunosuppressive treatment. ${ }^{5,6,20}$ Children 10 years old or younger were excluded from our analysis because they typically have a prodrome of diarrhea caused by Escherichia coli O157:H7, systemic microvascular thrombosis is uncommon, and their mortality is low..$^{21,22}$ Patients more than 10 years of age whose syndrome was associated with E. coli O157:H7 were also excluded. Patients who had a syndrome described as TTP or HUS that was associated with other conditions, such as systemic malignancy, ${ }^{23}$ hematopoietic stem cell transplantation, ${ }^{24}$ toxicity from cancer chemotherapy or immunosuppressive agents, immune-mediated drug reactions, and chronic systemic autoimmune disorders ${ }^{25}$ were excluded because the course of their illness is determined by their primary disorder. ${ }^{6}$ Patients with TTP that occurred during pregnancy or postpartum were included because these conditions are often a risk factor for TTP that may be described as idiopathic. ${ }^{26}$ Because the clinical history and associated conditions were often incompletely described, patients were included in our analysis if they had a diagnosis of TTP without further description. Article and patient selection and data extraction were performed independently by three of the authors (B.M.H., M.A.F., and J.N.G.).

\section{RESULTS}

\section{Article and patient characteristics}

Thirty of 292 retrieved articles reported cardiac abnormalities in 111 patients who may be described as having idiopathic TTP (Fig. 1). Of the 30 included articles, 16 were reports of single patients. ${ }^{1,27-41}$ Four additional articles were reports of two or three selected patients. ${ }^{42-45}$ For analysis related to study type, these 4 articles were characterized as case reports and analyzed together with the 16 reports of single patients. Plasma ADAMTS13 (a disintegrin and metalloprotease with thrombospondin-1-like repeats) activity, an important factor in the pathogenesis of idiopathic TTP, ${ }^{6}$ was described in two patients. In one, activity was described as absent with an inhibitor present; $^{36}$ in the other patient, ADAMTS13 activity was reported to be 13 percent at the time of a previous episode of TTP. ${ }^{45}$ Only $11(41 \%)$ of the 27 patients in these 20 case 


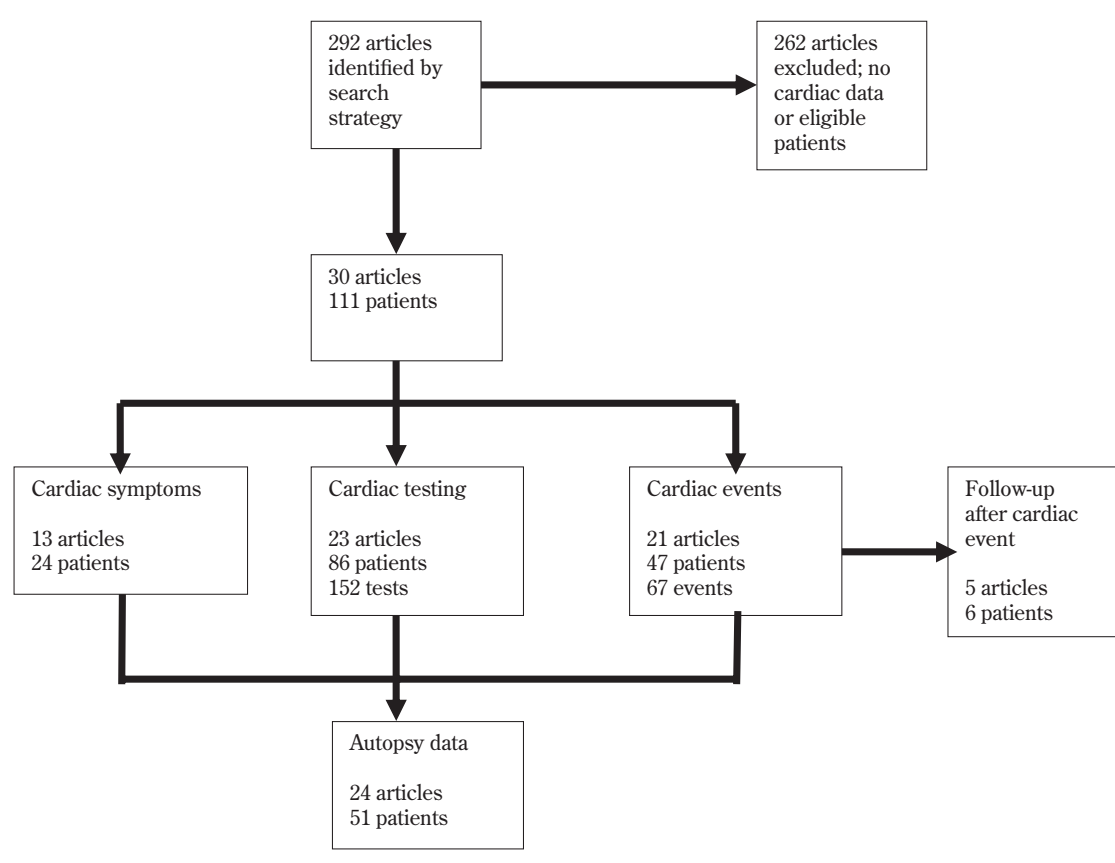

Fig. 1. Outline of articles identified and the articles and patients selected for analysis.

reports were treated with plasma exchange; $22(81 \%)$ died. The case reports are described in Table 1.

Nine articles were retrospective cohort studies ${ }^{2,3,46-52}$ and one article was a prospective cohort study. ${ }^{53}$ These studies described 398 total patients with TTP or HUS (6-220 total patients per article). Only 84 (22\%) patients (1-32 patients per article, median 3 patients per article), however, were eligible for our analysis, because they appeared to have idiopathic TTP and they also had cardiac symptoms, testing, or abnormalities. ADAMTS13 activity was not described in any of the patients. Fifty-two $(62 \%)$ of the 84 patients were treated with plasma exchange. Mortality could be assessed in 74 patients; 35 (47\%) died. These 10 cohort studies are described in Table 2.

Table 3 documents the numbers of patients from articles of each study type reporting cardiac symptoms, testing, events, follow-up, and autopsies. Table 4 describes the reported cardiac symptoms and events.

\section{Cardiac symptoms}

Cardiac symptoms were reported in 24 patients in 13 articles. $2,31-38,45,47,49,53$ Thirteen patients in 11 articles had symptoms described as chest or substernal pain or angina. ${ }^{2,31-35,38,45,47,49,53}$ Ten patients in 2 articles had symptoms consistent with congestive heart failure. ${ }^{36,47}$ One patient had syncope attributed to a cardiac origin. ${ }^{37}$

\section{Cardiac testing}

Cardiac testing was reported in 86 patients in 23 articles. 1 patient. ${ }^{43}$

\begin{abstract}
Electrocardiograms
Electrocardiograms (EKGs) were described in 79 patients in 23 articles. ${ }^{1-3,27-29,31-38,40,42-45,47,48,52,53}$ In 1 article 32 patients had EKGs but the frequency of abnormal EKGs among the patients was not described; ${ }^{52}$ in the other 47 patients the EKGs were described as abnormal in all but one. ${ }^{2}$ The most common abnormalities were sinus tachycardia $\quad(\mathrm{n}=16), 3,28,32,38,42,47,48 \quad$ ST segment elevation $(n=8), 3,32,35,37,38,40,45,53$ and nonspecific ST-T changes $(\mathrm{n}=7)^{3,34,44,47}$ Other EKG changes suggestive of ischemia were reported in an additional 6 patients. ${ }^{28,29,31,36,48,53}$ Less common abnormalities included ST segment depression $(\mathrm{n}=1)^{44}$ and sinus bradycardia $(\mathrm{n}=2))^{35,47}$ Atrial or supraventricular tachycardia $(\mathrm{n}=1),{ }^{42}$ atrioventricular dissociation or complete heart block $(\mathrm{n}=2),{ }^{42,47}$ and escape rhythm $(\mathrm{n}=1)$ were described in 2 articles. $^{42}$
\end{abstract}

\section{Echocardiograms}

Thirteen patients in 9 articles had echocardiograms; ${ }^{33,34,36-38,43-45,53} 1$ patient was reported to be normal. ${ }^{37}$ Five patients had wall motion abnormalities including hypokinetic or akinetic segments. ${ }^{33,34,38,45,53}$ Reduced left ventricular ejection fraction or dysfunction was described in 8 patients. ${ }^{34,38,44,53}$ Pericardial effusions were reported in 4 patients $\mathrm{s}^{34,38,44,53}$ and cardiac tamponade was reported in

\section{Coronary angiography}

Coronary angiography was reported for 2 patients. ${ }^{38,44}$ One angiogram demonstrated normal coronary arteries but generalized left ventricular hypokinesis and apical dyskinesis ${ }^{44}$ and one demonstrated normal epicardial coronaries but slow flow suggestive of small vessel disease. ${ }^{38}$

\section{Cardiac enzymes}

Twenty-six of 55 assessments of cardiac enzymes in 12 articles were abnormal. ${ }^{31-35,37,38,40,45,47,52,53}$ Twenty-two patients had elevated troponins but no information on creatine kinase or creatine kinase-MB fractions. ${ }^{34,35,37,40,45,52,53}$ Three abnormal tests were only elevated creatine kinase-MB fractions, ${ }^{32,33,38}$ whereas an additional 2 patients had elevated creatine kinase MB-fractions and also elevated troponin. ${ }^{34,35}$ One patient was reported to have abnormal cardiac enzyme levels but no further details were given. ${ }^{31}$ Only two studies provided information on the frequency of cardiac enzyme abnormalities. McCarthy and coworkers ${ }^{53}$ prospectively 


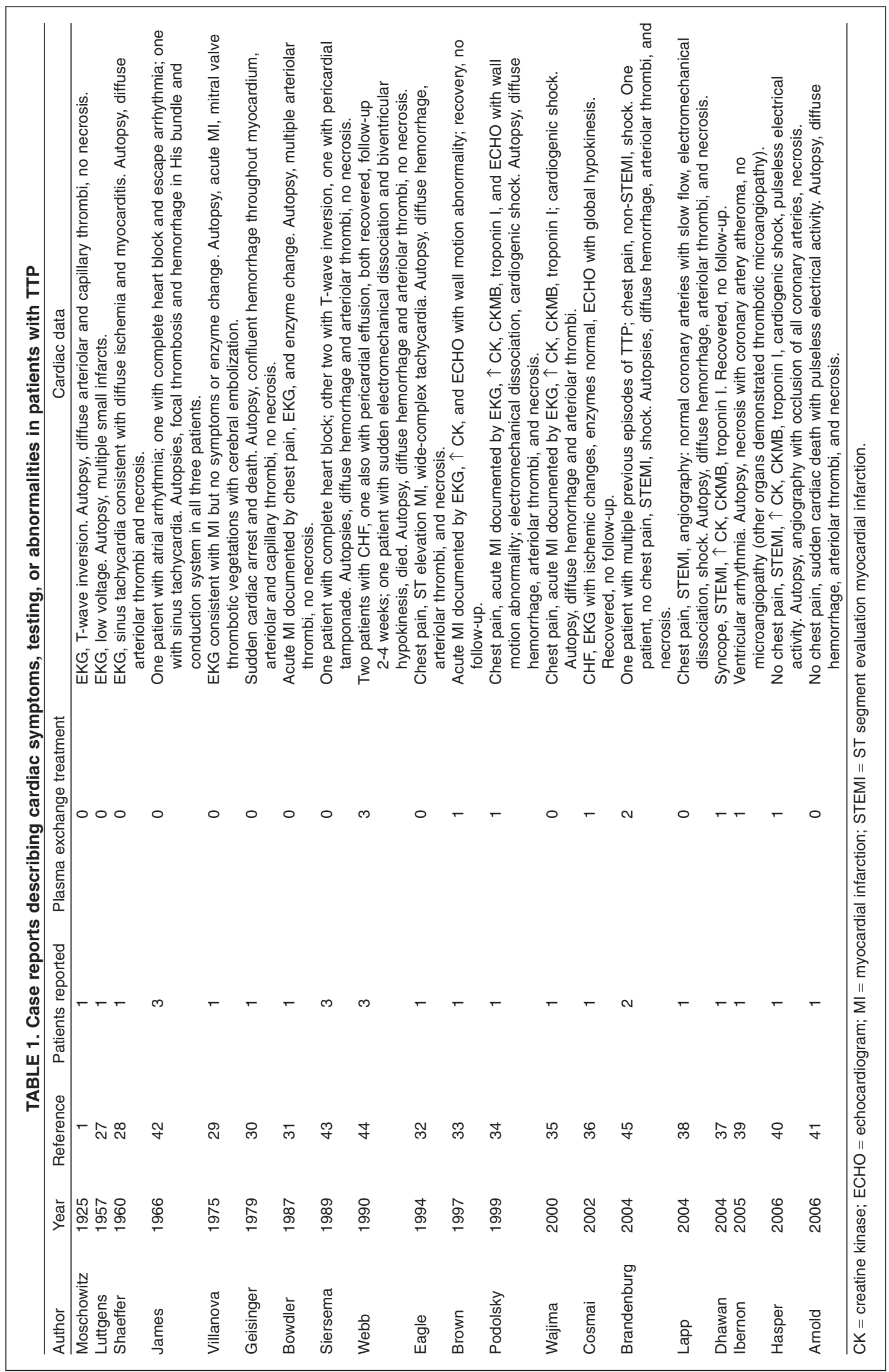




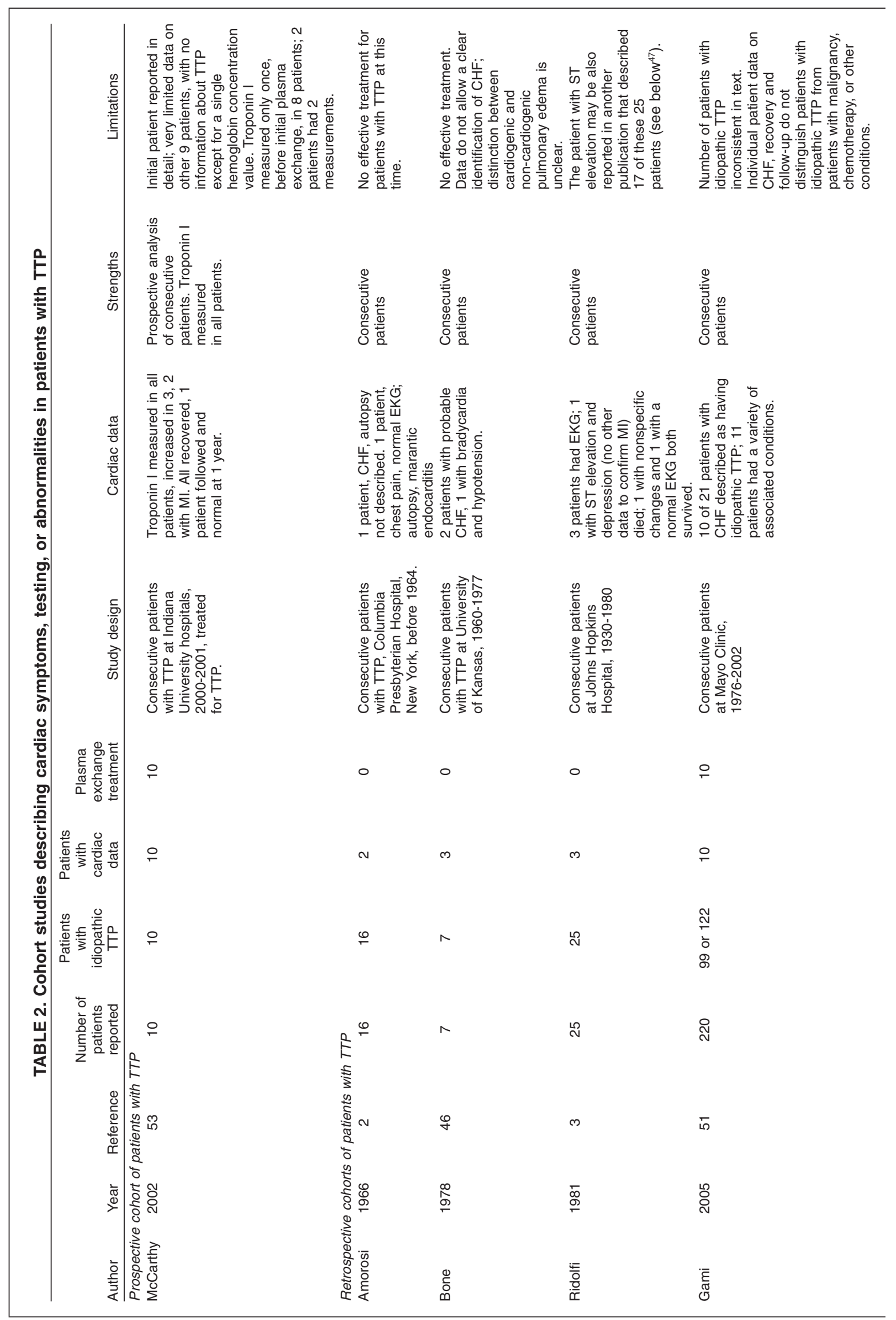




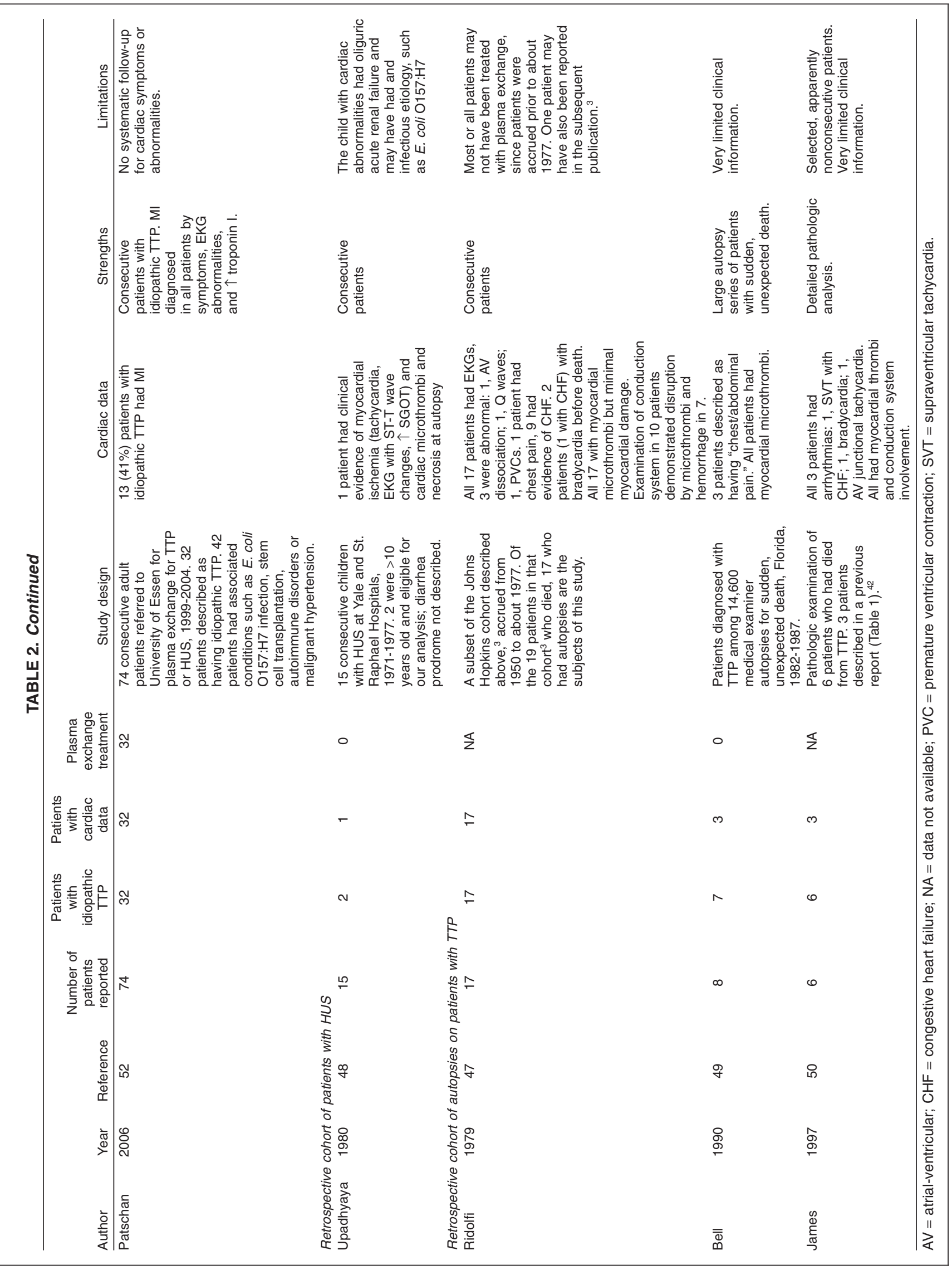


TABLE 3. Numbers of articles and patients with TTP with reports of cardiac symptoms, testing, events, and follow-up

\begin{tabular}{lccccc}
\hline & \multicolumn{5}{c}{ Clinical data on cardiac involvement* } \\
\cline { 2 - 6 } Study type & Symptoms & Testing & Events & Follow-up† & Autopsies \\
\hline Case reports (20) & $9(9)$ & $22(17)$ & $22(16)$ & $4(3)$ & $22(17)$ \\
Prospective cohort (1) & $1(1)$ & $10(1)$ & $3(1)$ & $1(1)$ & 0 \\
Retrospective cohorts (9) & $14(3)$ & $54(5)$ & $22(4)$ & $1(1)$ & $29(7)$ \\
Total (30) & $24(13)$ & $86(23)$ & $47(21)$ & $6(5)$ & $51(24)$ \\
\hline
\end{tabular}

* Data are reported as number of patients (number of articles).

$\dagger$ Sixteen patients who had cardiac events and survived were eligible for follow-up. Autopsies were reported for $51(93 \%)$ of the 55 patients who died; cardiac involvement was described in 48 of the 51 patients.

\begin{tabular}{|lr|}
\hline \multicolumn{2}{|c|}{ TABLE 4. Cardiac symptoms and events in } \\
patients with TTP
\end{tabular}

documented increased serum troponin I levels in 3 of 10 consecutive patients. ${ }^{53}$ Serum troponin was measured at the time of the first plasma exchange treatment; the relation to cardiac symptoms was not reported; 8 of 10 patients had only a single troponin I measurement. ${ }^{53}$ Patschan and colleagues ${ }^{52}$ retrospectively documented increased serum troponin I levels greater than $1 \mathrm{ng}$ per $\mathrm{mL}$ in 13 of $32(41 \%)$ consecutive patients. The frequency and timing of troponin measurements in relation to the onset of symptoms was not reported, but it was stated that the occurrence of acute myocardial infarctions was 2 to 11 days after presentation with TTP ${ }^{52}$ No studies reported measurements of B-natriuretic peptide.

\section{Cardiac events}

Forty-seven patients with TTP were described with a total of 67 cardiac events; 31 (66\%) of these patients died. Table 4 summarizes the major cardiac events.

Myocardial infarction was reported in 26 patients. Seven patients had ST-elevation myocardial infarc- tion $^{32,35,37,38,40,45,53}$ and 1 patient had a non-ST elevation myocardial infarction. ${ }^{45}$ The type of myocardial infarction was not described in the remaining 18 patients. ${ }^{31,33,34,52,53}$ Half of the 26 patients with acute myocardial infarction were reported in one study: 13 of 32 (41\%) patients in a retrospective cohort study. $^{52}$ In this study, patients who developed myocardial infarction had the same frequency of cardiac risk factors (diabetes, hypercholesterolemia, hypertension, and smoking) as patients without myocardial infarction. ${ }^{52}$ Patients with myocardial infarction had lower platelet counts and higher serum LDH levels, suggesting greater severity of TTP. ${ }^{52}$ Six (46\%) of the 13 patients with myocardial infarction died. ${ }^{52}$

Congestive heart failure was reported in 17 patients; $;^{34,43,44,46,50,51} 10$ of these patients were reported in one retrospective cohort study. ${ }^{51}$ In this study, heart failure was recognized on average 8 days after the diagnosis of TTP; it was suggested that mortality among patients with heart failure may be greater than in patients without heart failure..$^{51}$

Arrhythmias were described in 10 patients. Arrhythmias described as complete heart block or electromechanical dissociation were the most commonly reported arrhythmias, described in six patients. . $^{32,34,42-44,47}$ Two patients had supraventricular tachycardias, ${ }^{42,50}$ one patient had an atrial-ventricular junctional tachycardia, ${ }^{50}$ and one patient had a ventricular arrhythmia. ${ }^{39}$ Some of these arrhythmias may have been detected by telemetry, because they were not reported as abnormalities documented by EKG. Cardiogenic shock was reported in six patients ${ }^{38,40,45,46,53}$ and sudden cardiac death was reported in eight patients. . $^{30,41,43,46,49,50}$

\section{Follow-up after cardiac events}

Follow-up information was provided for 6 of the 16 patients who experienced a cardiac event and survived; the duration of follow-up was 10 days to 2 years (median, 7 weeks). ${ }^{33,36,44,46,53}$ Four patients were described as normal, although no cardiac testing was described; $33,36,46,53$ in 1 patient complete recovery was documented by a normal echocardiogram. ${ }^{44}$ One patient was described as having residual apical dyskinesis with radionuclide angiography. ${ }^{44}$

\section{Autopsy data}

Autopsies were reported for 51 patients; in 3 patients pathologic-histologic examination of the heart was not described, and myocardial involvement was described in 
all of the other 48 patients. The most common abnormalities were thrombi in arterioles and capillaries, described in 43 patients. ${ }^{1,2,27,28,30,32,34,35,38,41-45,47-50}$ In 32 patients myocardial hemorrhage was described. ${ }^{29-32,35,38,41-45,47,49}$ Twentytwo patients had evidence of recent myocardial infarction or necrosis. . $27,28,32,34,38-40,42,45,47,48$ Thirteen patients had involvement of the cardiac conduction system by hemorrhage or microvascular thrombi. ${ }^{43,47,49,50}$ Marantic endocarditis was described in 7 patients. . $27,29,34,43,47^{2}$

\section{DISCUSSION}

Although autopsy studies have demonstrated that the heart is among the most frequently involved organs in patients with $\mathrm{TTP}^{2-4,47}$ clinical evidence for cardiac involvement is surprisingly limited. Our search for all reported patients who had cardiac symptoms, testing, or abnormalities associated with idiopathic TTP identified only 30 articles describing 111 patients; 16 of these articles described only 1 patient each. Ten cohort studies were identified, one of which was a prospective study of 10 consecutive patients evaluated for cardiac ischemia, but this study had very limited clinical data (Table 2). ${ }^{53}$ The most important article was the retrospective cohort study by Patschan and colleagues ${ }^{52}$ that evaluated 74 consecutive patients for evidence of myocardial infarction; 32 patients were described as having idiopathic TTP and 13 (41\%) of these patients had evidence for myocardial infarction. This observation ${ }^{52}$ suggests that critical cardiac involvement in patients with TTP is more common than currently recognized and previously reported.

\section{Frequency and clinical importance of cardiac involvement}

Cardiac symptoms have been rarely reported during acute episodes of TTP. The low frequency of reported cardiac symptoms in patients with TTP may be attributed to several factors. The pentad of clinical features originally described by Amorosi and Ultmann ${ }^{2}$ emphasized neurologic and renal involvement and subsequent case series have commonly focused on these abnormalities. The common symptoms of dyspnea and weakness may be attributed to anemia rather than heart failure. Cardiac symptoms may also be overlooked because many patients are young, without cardiac risk factors.

There are limited data on the frequency of cardiac events in TTP. In the study of Patschan and coworkers, ${ }^{52}$ acute myocardial infarction was documented in 13 (41\%) of 32 patients by symptoms, EKG abnormalities, and increased serum levels of troponin I. Myocardial infarctions were diagnosed 2 to 11 days after the patients presented and plasma exchange was initiated. Six (46\%) of the 13 patients with myocardial infarction died..$^{52}$ McCarthy and colleagues ${ }^{52}$ identified elevated levels of troponin I in
3 of 10 (30\%) prospectively studied patients with $\mathrm{TTP}^{53}$ but these measurements were only made before beginning plasma exchange in 8 patients and therefore subsequent ischemia may not have been identified. All 3 patients with elevated serum troponin levels survived. ${ }^{53}$ These two studies suggest that routine cardiac enzyme screening in all patients with TTP is important to document the frequency of cardiac ischemia. Screening should continue beyond the initial presentation with TTP since myocardial infarction may not be detected until several days into the disease course. ${ }^{52}$ In the 2 patients who were reported to have coronary angiography, epicardial coronary arteries were normal, suggesting that microvascular thombi were the etiology of ischemia. ${ }^{38,44}$ This is consistent with the pathologic pattern of cardiac involvement in TTP and also similar to other disorders of microvascular cardiac disease. $^{54}$

Heart failure may also be a common cardiac manifestation of TTP. Gami and coworkers ${ }^{51}$ identified 10 patients with acute heart failure in 122 patients with idiopathic TTP using cardiac ultrasound and clinical criteria. Similar to myocardial infarction, congestive heart failure may only be recognized several days after the diagnosis of TTP and may be associated with increased mortality. ${ }^{51}$

Cardiac arrhythmias have only been described in case reports and their frequency cannot be estimated. No studies described the systematic use of telemetry.

\section{Persistent cardiac dysfunction}

We have previously documented that patients have both cognitive and physical limitations following recovery from $\mathrm{TTP}^{55,56}$ and persistent cardiac abnormalities may contribute to these symptoms. Follow-up evaluations of patients who have had cardiac events, however, have been reported in few patients and only for brief durations. ${ }^{51,52}$ Therefore, it remains unknown whether cardiac involvement may be responsible for symptoms of decreased endurance reported by some patients following recovery from TTP. ${ }^{56}$

\section{Therapy for cardiac dysfunction}

Whether targeted therapy for TTP patients with cardiac events may improve outcomes is unknown; we identified no information addressing this issue. Thrombocytopenia may limit the ability to perform some cardiac interventions, but noninvasive measures may be appropriate. For example, complete heart block was reported in three patients. Telemetry, not currently routine for patients with TTP, could immediately identify complete heart block, resulting in pacemaker placement to avoid sudden death. Early initiation of long-acting beta-blockers and renin-angiotensin-aldosterone system blockers in acute myocardial infarction with associated left ventricular 
dysfunction improves mortality in non-TTP patients; ${ }^{57}$ similar benefit may occur in TTP patients with ischemic cardiac events.

\section{Study limitations}

Our systematic review has important limitations. Biased selection of reported patients was likely in almost all articles, reflected by the rare reports of normal cardiac tests. We accepted the accuracy of the diagnosis of TTP, although data were incomplete in most patients. Our effort to select patients with idiopathic TTP, rather than patients whose syndrome may have been associated with drug toxicity, malignancy, or a systemic autoimmune disorder, was often unclear because of limited clinical data. ADAMTS13 activity was not reported in any of the cohort studies; only two patients among the case reports had ADAMTS13 activity described, and both were deficient. ${ }^{36,45}$ Many of the patient descriptions were from the era before effective treatment with plasma exchange, making some observations less relevant to current practice.

None of the four questions that formed the basis for our review were answered satisfactorily. The frequency of cardiac abnormalities, the contribution of cardiac abnormalities to mortality and morbidity, and the potential role for targeted cardiac treatment could not be determined from published reports.

\section{Conclusions and recommendations}

Few studies have investigated cardiac involvement in TTP, but the limited data suggest that cardiac involvement may be a common and important cause of continuing mortality. Cardiac dysfunction may persist in TTP survivors, though its potential impact on health and quality of life remains to be determined. We anticipate that better screening for cardiac involvement, both systematic evaluation for cardiac symptoms and sensitive cardiac testing, will identify a high frequency of cardiac abnormalities in patients with TTP. Confirmation of this hypothesis will require prospective studies of consecutive patients with long-term follow-up using current diagnostic methods to diagnose $\mathrm{TTP}^{6}$ and possible cardiac abnormalities to define the incidence of cardiac involvement, to determine if targeted cardiac therapy improves survival, and to assess whether cardiac dysfunction may be persistent following recovery.

In the absence of clear evidence for cardiac involvement, we recommend that all patients who present with
TTP be screened with a focused cardiac history, electrocardiogram, and serial cardiac enzymes and monitored with telemetry (Fig. 2). Echocardiography, consultation with a cardiologist, and targeted cardiac therapy should be considered if any abnormalities are identified.

\section{REFERENCES}

1. Moschcowitz E. An acute febrile pleiochromic anemia with hyaline thrombosis of the terminal arterioles and capillaries. Arch Intern Med 1925;36:89-93.

2. Amorosi EL, Ultmann JE. Thrombotic thrombocytopenic purpura: report of 16 cases and review of the literature. Medicine 1966;45:139-59.

3. Ridolfi RL, Bell WR. Thrombotic thrombocytopenic purpura. Report of 25 cases and review of the literature. Medicine 1981;60:413-28.

4. Hosler GA, Cusumano AM, Hutchins GM. Thrombotic thrombocytopenic purpura and hemolytic uremic syndrome are distinct pathologic entities. A review of 56 autopsy cases. Arch Pathol Lab Med 2003;127:834-9.

5. Rock GA, Shumak KH, Buskard NA, Blanchette VS, Kelton JG, Nair RC, Spasoff RA. Comparison of plasma exchange with plasma infusion in the treatment of thrombotic thrombocytopenic purpura. N Engl J Med 1991;325:393-7.

6. George JN. Thrombotic thrombocytopenic purpura. N Engl J Med 2006;354:1927-35.

7. Bell WR, Braine HG, Ness PM, Kickler TS. Improved survival in thrombotic thrombocytopenic purpura-hemolytic uremic syndrome. N Engl J Med 1991;325:398-403.

8. Bobbio-Pallavicini E, Porta C, Fornasari PM, Viarengo G, Ascari E. Thrombotic thrombocytopenic purpura (TTP). Retrospective study of 84 patients and therapeutic prospects. Transfus Sci 1992;13:39-44.

9. Goodnough LT, Strasburg D, Verbrugge D, Fisher C. 
Morbidity and mortality in adults with "idiopathic" thrombotic thrombocytopenic purpura/hemolytic uremic syndrome. J Intensive Care Med 1994;9:167-71.

10. Hayward CP, Sutton DM, Carter WH Jr, Campbell ED, Scott JG, Francombe WH, Shumak KH, Baker MA. Treatment outcomes in patients with adult thrombotic thrombocytopenic purpura-hemolytic uremic syndrome. Arch Intern Med 1994;154:982-7.

11. Dawson RB, Brown JA, Mahalati K, Sapsiri S, Pearlman S, Gulden D, Bilenki L, Wenk RE. Durable remissions following prolonged plasma exchange in thrombotic thrombocytopenic purpura. J Clin Apher 1994;9:112-5.

12. Conlon PJ, Howell DN, Macik G, Kovalik EC, Smith SR. The renal manifestations and outcome of thrombotic thrombocytopenic purpura/hemolytic uremic syndrome in adults. Nephrol Dial Transplant 1995;10:1189-93.

13. Lara PN Jr, Coe TL, Zhou H, Fernando L, Holland PV, Wun T. Improved survival with plasma exchange in patients with thrombotic thrombocytopenic purpura-hemolytic uremic syndrome. Am J Med 1999;107:573-9.

14. Mori Y, Wada H, Tamaki S, Minami N, Shiku H, Ihara T, Omine M, Kakisita E. Outcome of thrombotic thrombocytopenic purpura and hemolytic uremic syndrome in Japan. Clin Appl Thromb Hemost 1999;5:110-2.

15. Veyradier A, Obert B, Houllier A, Meyer D, Girma JP. Specific von Willebrand factor-cleaving protease in thrombotic microangiopathies: a study of 111 cases. Blood 2001;98: 1765-72.

16. Chang JC, Kathula SK. Various clinical manifestations in patients with thrombotic microangiopathy. J Invest Med 2002;50:201-6.

17. Vesely SK, George JN, Lammle B, Studt J-D, Alberio L, El-Harake MA, Raskob GE. ADAMTS13 activity in thrombotic thrombocytopenic purpura-hemolytic uremic syndrome: relation to presenting features and clinical outcomes in a prospective cohort of 142 patients. Blood 2003; 101:60-8.

18. Raife TJ, Atkinson B, Montgomery RR, Vesely SK, Friedman K. Severe deficiency of VWF-cleaving protease (ADAMTS13) activity defines a distinct population of thrombotic microangiopathy patients. Transfusion 2004; 44:146-50.

19. Cook DJ, Mulrow CD, Haynes RB. Systematic reviews: synthesis of best evidence for clinical decisions. Ann Intern Med 1997;126:376-80.

20. Allford S, Hunt BJ, Rose P, Machin S; Haemostasis and Thrombosis Task Force. Guidelines on the diagnosis and management of the thrombotic microangiopathic haemolytic anemias. Br J Haematol 2003;120:556-73.

21. Siegler R, Oakes R. Hemolytic uremic syndrome; pathogenesis, treatment, and outcome. Curr Opin Pediatr 2005; 17: 200-4.

22. Tarr PI, Gordon CA, Chandler WL. Shiga-toxin-producing Escherichia coli and haemolytic uraemic syndrome. Lancet 2005;365:1073-86.
23. Francis KK, Kalyanam N, Terrell DR, Vesely SK, George JN. Disseminated malignancy misdiagnosed as thrombotic thrombocytopenic purpura: a report of 10 cases and a systematic review of the literature. Oncologist 2007;12:11-9.

24. Kojouri K, George JN. Thrombotic microangiopathy following allogeneic hematopoietic stem cell transplantation. Curr Opin Oncol 2007;19:148-54.

25. George JN, Vesely SK, Terrell DR. The Oklahoma thrombotic thrombocytopenic purpura-hemolytic uremic syndrome (TTP-HUS) registry: a community perspective of patients with clinically diagnosed TTP-HUS. Semin Hematol 2004;41:60-7.

26. George JN. The association of pregnancy with thrombotic thrombocytopenic purpura-hemolytic uremic syndrome. Curr Opin Hematol 2003;10:339-44.

27. Luttgens WF. Thrombotic thrombocytopenic purpura with hemorrhagic gangrene of the skin and subcutaneous tissue: report of a case. Ann Intern Med 1957;46:1207-13.

28. Shaeffer W, Collings H. Thrombotic thrombocytopenic purpura: report of a case and review of the literature. Guthrie Clin Bull 1960;29:181-92.

29. Villanova JR, Norenberg MD, Stuard ID. Thrombotic thrombocytopenic purpura; systemic embolization from nonbacterial thrombotic endocarditis. N Y State Med J 1975;75:2246-8.

30. Geisinger KR, Solomon AR. Sudden cardiac death in thrombotic thrombocytopenic purpura. Arch Pathol Lab Med 1978;103:599-600.

31. Bowdler AJ. Chronic relapsing thrombotic thrombocytopenic purpura. South Med 1987;80:507-10.

32. Eagle KA, Fallon JT. Case records of the Massachusetts General Hospital. A 41 year old woman with thrombocytopenia, anemia, and sudden death. N Engl J Med 1994; 331:661-7.

33. Brown SA, Popat S, Carr R. An unusual cause of chest pain-thrombotic thrombocytopenic purpura presenting with chest pain. Postgrad Med J 1997;73:825-7.

34. Podolsky SH, Zembowicz A, Schoen FJ, Benjamin RJ, Sonna LA. Massive myocardial necrosis in thrombotic thrombocytopenic purpura-a case report and review of the literature. Arch Pathol Lab Med 1999;123:937-40.

35. Wajima T, Jonson EH. Sudden cardiac death from thrombotic thrombocytopenic purpura. Clin Appl Thromb Hemost 2000;6:108-10.

36. Cosmai EM, Puzis L, Tsai HM, Lian EC. Thrombocytopenic purpura and ardiomyopathy in pregnancy reversed by combined plasma exchange and infusion. Eur J Haematol 2002;68:239-42.

37. Dhawan S, Tak T. Myocardial infarction in a patient with thrombotic thrombocytopenic purpura. Int J Cardiol 2004; 95:339-41.

38. Lapp H, Shin DI, Kroells W. Cardiogenic shock due to thrombotic thrombocytopenic purpura. Z Kardiol 2004;93: 486-92.

39. Ibernon M, Moresco F, Carreras L. Thrombotic thrombocy- 
topenic purpura with severe large artery branch involvement. Nephrol Dial Transplant 2005;20:467-8.

40. Hasper D, Schrage D, Niesporek S, Knollmann F, Barckow D, Oppert M. Extensive coronary thrombosis in thrombotic thrombocytopenic purpura. Int J Cardiol 2006;106:407-9.

41. Arnold PO, Klink D, Holmes AK. Fatal cardiac arrhythmia in a patient with thrombotic thrombocytopenic purpura. Am J Med Sci 2006;331:320-1.

42. James TN, Monto RW. Pathology of the cardiac conduction system in thrombotic thrombocytopenic purpura. Ann Intern Med 1966;65:37-43.

43. Siersema PD, Kros JM, van den Berg B. Cardiac manifestations of thrombotic thrombocytopenic purpura. Neth J Med 1989;35:100-7.

44. Webb JG, Butany J, Langer G, Scott JG, Liu PP. Myocarditis and myocardial hemorrhage associated with thrombotic thrombocytopenic purpura. Arch Intern Med 1990;150: 1535-7.

45. Brandenburg VM, Gaertner S, Lindemann-Docter K, Ortlepp JR, Westerhuis R, Ketteler M, Westenfeld R, Floege J. Underestimated complications in thrombotic thrombocytopenic purpura-haemolytic uraemic syndrome. Nephrol Dial Transplant 2004;19:2142-6.

46. Bone RC, Henry JE, Petterson J, Amare M. Respiratory dysfunction in thrombotic thrombocytopenic purpura. Am J Med 1978;65:262-70.

47. Ridolfi RL, Hutchins GM, Bell WR. The heart and cardiac conduction system in thrombotic thrombocytopenic purpura: a clinicopathologic study of 17 autopsied patients. Ann Intern Med 1979;91:357-63.

48. Upadhyaya K, Barwick K, Fishaut M, Kashgarian M, Siegel NJ. The importance of non-renal involvement in hemolytic-uremic syndrome. Pediatrics 1980;65:115-20.
49. Bell MD, Barnhart JS, Martin JM. Thrombotic thrombocytopenic purpura causing sudden, unexpected death-a series of eight patients. J Forensic Sci 1990;35:601-13.

50. James TN, Alperin JB. Apoptotic myocardial degeneration in thrombotic thrombocytopenic purpura. Apoptosis 1997; 2:384-94.

51. Gami AS, Hayman SR, Grande JP, Garovic VD. Incidence and prognosis of acute heart failure in thrombotic microangiopathies. Am J Med 2005;118:544-7.

52. Patschan D, Witzke O, Dührsen U, Erbel R, Philipp T, Herget-Rosenthal S. Acute myocardial infarction in thrombotic microangiopathies-clinical characteristics, risk factors, and outcome. Nephrol Dial Transplant 2006;21: 1549-54.

53. McCarthy LJ, Danielson CF, Skipworth EM, Peters SL, Miraglia CC, Antony AC. Myocardial infarction/injury is relatively common at presentation of acute thrombotic thrombocytopenic purpura: the Indiana University experience. Ther Apher 2002;6:2-4.

54. Camici PG, Crea F. Coronary microvascular dysfunction. N Engl J Med 2007;356:830-40.

55. Ware JE, Kosinski M, Dewey JE. How to score version two of the SF-36 health survey. Lincoln (RI): QualityMetric Inc.; 2000.

56. Lewis QF, Terrell DR, Vesely SK, George JN. Long-term abnormalities of patient-reported outcomes after recovery from thrombotic thrombocytopenic purpura (TTP) using health-related quality-of-life (QOL) measurements. Blood 2006;108:139a-140a.

57. Maggioni AP, Latini R. How to use ACE inhibitors, [beta]-blockers, and newer therapies in AMI. Am Heart J 1999;139:S183-7. 